\title{
Vitrification of immature and matured bovine oocytes: effect of brilliant cresyl blue selection and hyaluronan addition
}

\author{
P. Rodriguez-Villamil ${ }^{1}$, F.L. Ongaratto ${ }^{1}$, G. Moreira $^{1}$, M. Fernandez Taranco ${ }^{1}$, G.A. Bó ${ }^{1,2,3}$ \\ ${ }^{1}$ Instituto de Reproducción Animal Córdoba (IRAC), Córdoba, Argentina. \\ ${ }^{2}$ Instituto de Ciencias Básicas y Aplicadas, Universidad Nacional de Villa María, Córdoba, Argentina.
}

\begin{abstract}
The aim of the present study was to evaluate the effect of brilliant cresyl blue (BCB) selection, the type of oocyte (immature or matured) and the use of hyaluronan in the vitrification solution on further embryo developmental competence. Oocytes $(n=1308)$ obtained from abattoir ovaries were classified by BCB stain. Control oocytes were maintained in holding media for $90 \mathrm{~min}$ and then subdivided to be placed into maturation media without any treatment or were vitrified. Immature or matured oocytes were vitrified by the solid-surface technique using two different vitrification solutions. VS1: composed of $10 \%$ ethylene glycol (EG) for $10 \mathrm{~min}$ followed by $20 \% \mathrm{EG}+0.2 \mathrm{M}$ trehalose for $30 \mathrm{sec}$ and finally into $30 \% \mathrm{EG}+0.5 \mathrm{M}$ trehalose for $30 \mathrm{sec}$, or VS2 composed by $10 \%$ EG for $10 \mathrm{~min}$, followed by $20 \% \mathrm{EG}+0.2 \mathrm{M}$ trehalose for 30 $\mathrm{sec}$, and finally into $30 \% \mathrm{EG}+0.5 \mathrm{M}$ trehalose +0.1 $\mathrm{g} / \mathrm{ml}$ hyaluronan for $30 \mathrm{sec}$. Oocytes were then loaded into Fyberplugs ${ }^{\mathrm{TM}}$ and vitrified. After one week, Fyberplugs ${ }^{\mathrm{TM}}$ were open and placed directly into $\left(37^{\circ} \mathrm{C}\right)$ $0.5 \mathrm{M}$ sucrose solution for $5 \mathrm{~min}$, then into $0.25 \mathrm{M}$ of sucrose for another $5 \mathrm{~min}$ and finally placed into maturation medium for in vitro production. Cleavage and development rates were examined on days 2 and 7 after fertilization, respectively. The blastocyst rate of vitrified oocytes selected as $\mathrm{BCB}+(5.5 \pm 0.6 \%)$ were higher than those selected as BCB $-(1.0 \pm 0.4 \%)$ and those that were not selected by $\mathrm{BCB}(2.0 \pm 1.1 \% ; \mathrm{P}<0.001)$. Furthermore, immature vitrified oocytes had greater $(\mathrm{P}<0.05)$ cleavage and blastocyst rates $(44.8 \pm 1.9 \%$ and $4.0 \pm 0.6 \%)$ than matured vitrified oocytes $(38.3 \pm 2.8 \%$ and $2.5 \pm 0.6 \%$ ). Finally, the addition of hyaluronan to the vitrification solution had no significant effect on development rates. In conclusion, the selection of oocytes by $\mathrm{BCB}$ and the use of immature oocytes increase the development rates of vitrified-warmed oocytes.
\end{abstract}

Keywords: BCB, cryopreservation, hyaluronan, oocyte selection.

\section{Introduction}

Cryopreservation of semen and embryos nowadays is used successfully for the preservation and widespread distribution of animal genetics around the world. However, oocytes are much more difficult to cryopreserve than embryos due to their morphology, higher cryosensitivity and low hydraulic conductivity (Leibo, 1980; Ambrosini et al., 2006). Although, several experiments have been performed using different vitrification protocols with matured and immature bovine oocytes (Vajta et al., 1998; Men et al., 2002; Albarracin 2005; Magnusson et al., 2008; Morato et al., 2008; Vieira et al., 2008; Sripunya et al., 2010, Zhou et $a l ., 2010)$, survival rates after warming have been low, with embryo production rates between 0 to $13 \%$ (Vajta et al., 1998; Dinnyes et al., 2000; Morato et al., 2008; Sripunya et al., 2010; Zhou et al., 2010).

One of the alternatives to enhance survival rates after vitrification may be the selection of more competent oocytes for cryopreservation using a different technique other than the subjective evaluation of the oocyte morphology with a stereomicroscope, as is done today for commercial in vitro embryo production (De Loos et al., 1992). The brilliant cresyl blue (BCB) is a supravital staining technique that has been used successfully to identify the most competent oocytes in several species such as caprine (Rodriguez-Gonzalez et al., 2002, 2003; Urdaneta et al., 2003), equine (Pereira et al., 2010), porcine (Wongsrikeao et al., 2006; Antosik et al., 2009; Ishizaki et al., 2009; Pawlak et al., 2011), bubaline (Manjunath et al., 2007; Heleil and Fayed, 2010), murine (Wu et al., 2007), and bovine (Pujol et al., 2004; Alm et al., 2005; Ghanem et al., 2007; Opiela et al., 2008; Torner et al., 2008; Hadi et al., 2010; Silva et al., 2013). The BCB technique estimates the activity of glucose-6-phosphate dehydrogenase (G6PDH), an enzyme that is synthesized in growing oocytes, but with decreased activity when oocytes have finished their growing phase (Tian et al., 1998). The evaluation is relatively simple, because oocytes exposed to $\mathrm{BCB}$ show a blue coloration when the cytoplasm has low G6DPH levels, because they do not reduce $\mathrm{BCB}$ to a colorless compound. Thus, this stain is a tool that could be used to enhance the selection of oocytes by visual evaluation and provides a more selected group of competent oocytes that could be vitrified and/or matured in vitro for embryo production. Hadi et al. (2010) have shown that selection by BCB staining increased the survival rates of vitrified 
immature oocytes; however, they only evaluated nuclear maturation and did not make an attempt to produce embryos in vitro.

Another unresolved question in relation to oocyte cryopreservation has been the possibility of using mature or immature oocytes. Although several reports have shown that oocyte survival after cryopreservation for mature $v s$. immature oocytes are different (Hurtt et al., 2000; Men et al., 2002; Albarracin et al., 2005; Magnusson et al., 2008; Zhou et al., 2010), the results have been controversial and require further investigation.

Hyaluronan is a glycosaminoglycan that has shown to have an important role in cell proliferation, cell migration, cell differentiation and gene expression regulation (Toole, 2001) and has been used as replacement for bovine serum in embryo media (Palasz et al., 2006). Its use into bovine culture has been shown to increase in vitro embryo development rates and survival rates after cryopreservation (Stojkovic et al., 2002; Dattena et al., 2007; Palasz et al., 2006, 2008; Sheehan et al., 2007; Block et al., 2009). Furthermore, hyaluronan has been used as a biopolymer for slowrelease administration of FSH due to its molecular weight and chemical characteristics (Tríbulo et al, 2011). In aqueous solutions, hyaluronan has a tendency to form a three-dimensional network (Kobayashi et al., 1994), retaining critical concentrations in a diminutive volume of fluid surrounding the oocyte or embryo. Therefore, it could be used as a less toxic and more stable extracellular cryoprotectant into the vitrification solution, that could increase the developmental rates of vitrified-thawed oocytes regardless of the stage. The aim of the present study was to evaluate the effect of $\mathrm{BCB}$ on oocyte selection previous to cryopreservation and the addition of a biopolymer such as hyaluronan to the vitrification solution on developmental competence of immature and mature oocytes after vitrification.

\section{Materials and Methods}

\section{Experimental design and allocation of treatments}

Except where otherwise indicated, all chemicals were obtained from Sigma Chemical Co. (St. Louis, MO, USA).

The study involved the vitrification of immature $(\mathrm{n}=496)$ and in vitro matured $(\mathrm{n}=392)$ oocytes selected by BCB and vitrified in two different solutions as shown in Fig. 1. Immature $\mathrm{COCs}$ were selected by the $\mathrm{BCB}$ stain method (BCB + or BCB-) and then randomly subdivided to be matured or not before vitrification using two solutions (VS1 or VS2). A group of immature COCs (Control fresh group, $\mathrm{n}=220$ ) were maintained in holding medium (Vigro ${ }^{\circledR}$ Holding, Bioniche Animal Health, Belleville, ON, Canada) for 90 min, as those that were exposed to the BCB stain, and then directly matured fertilized and cultured; whereas another group of COCs were also maintained in holding medium for $90 \mathrm{~min}$ (Control vitrified, $\mathrm{n}=200$ ) and were vitrified using the VS1 solution and then thawed, matured, fertilized and cultured in vitro. The study was performed in 10 replicates and approximately 120 to 150 oocytes were processed in each replicate.

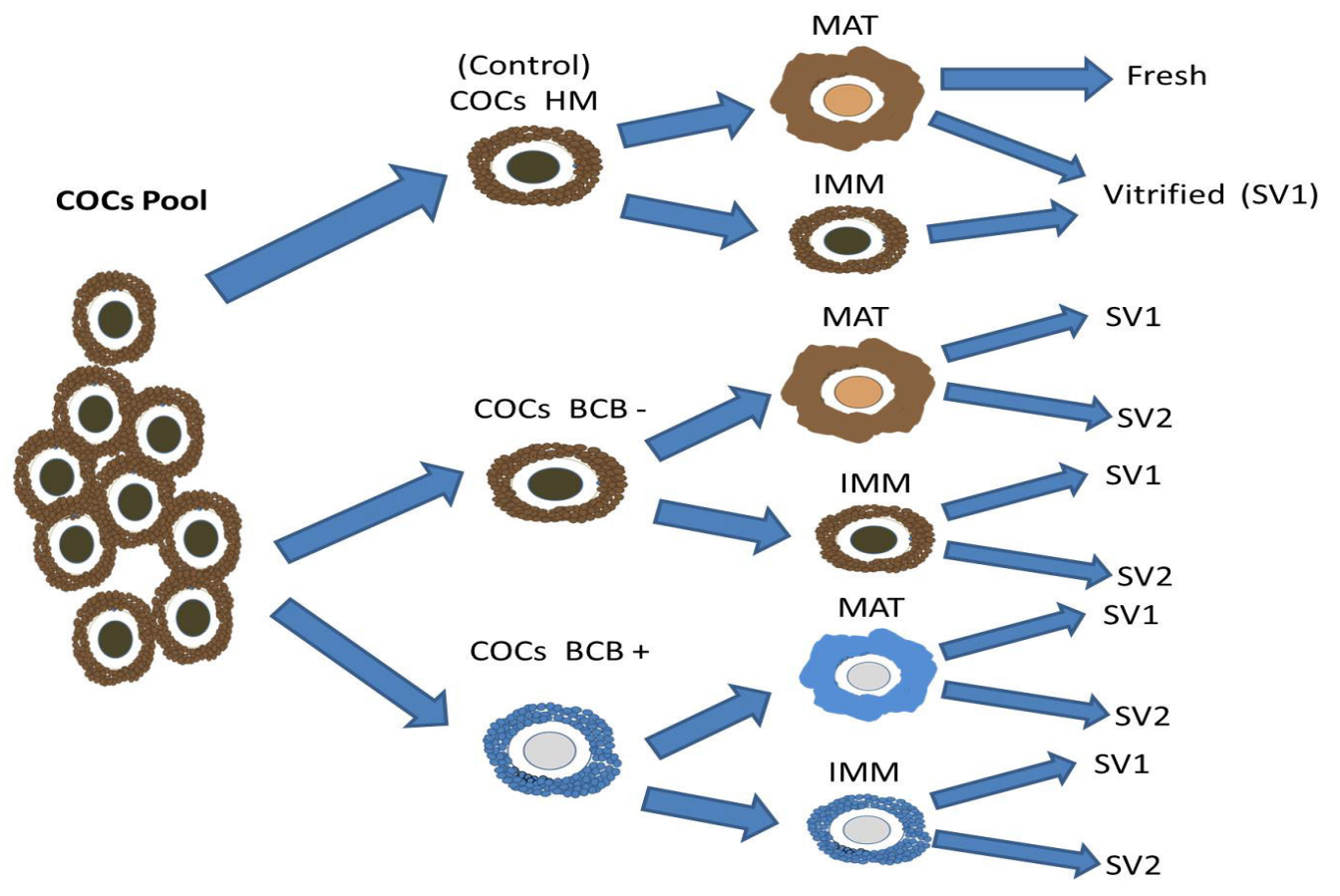

Figure 1. Experimental design. COCs: Cumulus-oocyte complexes; BCB+ or BCB-: Brillant cresyl blue positive or negative COCs; MAT: COCs matured in vitro; IMM: immature COCs; VS1 and VS2: vitrification solutions. 
Rodriguez-Villamil et al. Brilliant cresyl blue oocyte selection for vitrification.

\section{Oocyte source}

Bovine ovaries from Angus cross-breed cows obtained from a local abattoir were transported to the laboratory within $2-4 \mathrm{~h}$ after slaughter, at $24-32^{\circ} \mathrm{C}$, into Dulbecco's phosphate buffer saline. Cumulus-oocyte complexes (COCs) were aspirated from follicles $2-8 \mathrm{~mm}$ in diameter, washed in holding medium and classified according to morphological characteristics and only those with evenly granulated cytoplasm and surrounded by a compact and dense cumulus cell layer were used (De Loos et al., 1992).

\section{Brilliant cresyl blue staining}

The BCB staining was performed following the protocol indicated by Alm et al. (2005). Immediately after morphological selection, COCs were alocated in 100 $\mu \mathrm{l}$ drops of $26 \mu \mathrm{m}$ BCB (Sigma, B-5388) in modified PBS containing $1.090 \mathrm{mg} / \mathrm{ml}$ glucose, $35.2 \mathrm{mg} / \mathrm{ml} \mathrm{(mol} / \mathrm{l})$ pyruvate, $0.4 \%(\mathrm{w} / \mathrm{v})$ BSA fraction V (Sigma A-9647), and incubated at $38.8^{\circ} \mathrm{C}$, in a humidified atmosphere with $5 \% \mathrm{CO}_{2}$ for $90 \mathrm{~min}$. After the incubation time, the oocytes were observed under stereomicroscope and classified according to $\mathrm{BCB}$ staining as: $\mathrm{BCB}+($ oocytes with dark blue cytoplasm) or BCB- (oocytes with colorless cytoplasm). The control group were oocytes incubated for $90 \mathrm{~min}$ and placed in maturation media without any exposure to the stain.

\section{Vitrification and warming}

For vitrification, oocytes (in vitro matured or immature) were exposed to two different vitrification solutions. Oocytes vitrified in VS1 were first exposed to a solution containing $10 \%(\mathrm{v} / \mathrm{v})$ ethylene glycol (EG, Sigma E-9129) in holding medium for $10 \mathrm{~min}$ for initial oocyte cryoprotectant saturation (Papis et al., 2000). Then, groups of 5-6 COCs were placed in $20 \% \mathrm{EG}+0.2 \mathrm{M}$ trehalose solution for $30 \mathrm{sec}$ and subsequently in a $30 \% \mathrm{EG}+0.5 \mathrm{M}$ trehalose solution for $30 \mathrm{sec}$. Oocytes Vitrified in VS2 were first exposed to a $10 \% \mathrm{EG}$ solution for $10 \mathrm{~min}$, then 5-6 COCs were placed in a $20 \% \mathrm{EG}+0.2 \mathrm{M}$ trehalose solution for $30 \mathrm{sec}$, and finally into $30 \% \mathrm{EG}+0.5 \mathrm{M}$ trehalose $+0.1 \mathrm{mg} / \mathrm{ml}$ of hyaluronan for $30 \mathrm{sec}$. Oocytes exposed to the vitrification solution $(1 \mu \mathrm{l})$ were then loaded into Fyberplugs ${ }^{\mathrm{TM}}$ and were vitrified using the Solid Surface Cryologic Vitrification Method (CVM, Cryologic Inc., Victoria, Australia) as previously described (Rodriguez-Villamil et al., 2013). Vitrified oocytes were stored in liquid nitrogen for at least one week. After that period embryos were thawed by placing the Fiberplugs ${ }^{\mathrm{TM}}$ directly into a $0.5 \mathrm{M}$ sucrose solution (in holding medium) warmed at $37^{\circ} \mathrm{C}$ for $5 \mathrm{~min}$ and then into a $0.25 \mathrm{M}$ sucrose solution for another $5 \mathrm{~min}$ and finally placed into TCM-199 culture medium.
In vitro maturation

Previously vitrified and non-vitrified COCs were matured as previously described (RodriguezVillamil et al, 2013). Briefly, COCs were matured in $500 \mu 1$ drops in a 96-well culture plate (30-50 COCs in each well) and matured at $38.8^{\circ} \mathrm{C}$ in a moist atmosphere of $5 \% \mathrm{CO}_{2}$ in air for $24-26 \mathrm{~h}$. The maturation medium consisted of TCM-199 supplemented with $10 \%(\mathrm{v} / \mathrm{v})$ fetal bovine serum, $0.2 \mathrm{mM}$ sodium pyruvate, $35 \mathrm{mg} / \mathrm{ml}$ of porcine FSH (Folltropin-V, Bioniche Animal Health) and antibiotics.

\section{Fertilization and embryo culture}

COCs were fertilized and cultured as previously described (Rodriguez-Villamil et al., 2013). For fertilization, each straw of frozen semen of an Angus bull was thawed for $1 \mathrm{~min}$ at $37^{\circ} \mathrm{C}$, sperm were selected using Percoll discontinuous gradient (45 and $90 \%)$. In summary, the $90 \%$ Percoll solution $(500 \mu \mathrm{l})$ was placed in a 2-ml Eppendorf tube, and 500 ul of $45 \%$ Percoll were smoothly layered on this. Frozen-thawed semen was layered on top of gradients and tubes were centrifuged for $15 \mathrm{~min}$ at $700 \times \mathrm{g}$. The pellets were resuspended in the same amount of sperm-TALP medium and centrifuged for $5 \mathrm{~min}$ at $700 \times \mathrm{g}$. The supernatant was removed and the final concentration of the sperm pellet was adjusted with Fert-TALP to $1 \times 10^{6} \mathrm{sperm} / \mathrm{ml}$ for fertilization. COCs were fertilized in $500 \mu \mathrm{l}$ droplets (30-50 COCs/droplet) covered with mineral oil into modified TALP fertilization medium. After $20 \mathrm{~h}$ of in vitro fertilization, the COCs were vortexed to remove the cumulus cells and excess sperm, washed once in culture medium and transferred into $500 \mu \mathrm{l}$ drops of SOF culture medium under mineral oil in a controlled atmosphere $(5 \% \mathrm{CO} 2,5 \% \mathrm{O} 2$, and $90 \% \mathrm{~N} 2)$ at $38.8^{\circ} \mathrm{C}$ for 7 days.

\section{Assessment of in vitro development}

Cleavage rates of oocytes to the two-cell stage and development rates to the blastocyst stage were examined on days 2 and 7 after fertilization, respectively.

\section{Statistical analysis}

Cleavage and blastocyst rates were transformed by square root and then analyzed by ANOVA, considering maturation, $\mathrm{BCB}$ stain and vitrification solutions as main effects and their interactions. The Protected Least Significant Difference (LSD) test was used for subsequent multiple comparisons when ANOVA revealed statistically significant differences $(\mathrm{P}<0.05)$. All data were analyzed using the software Infostat (UNC, Argentina, 2010). 
Rodriguez-Villamil et al. Brilliant cresyl blue oocyte selection for vitrification.

\section{Results}

The effects of BCB staining on developmental and cleavage rates are depicted in Table 1. Cleavage and development rates of vitrified oocytes were greater for those selected as $\mathrm{BCB}+$ than those selected as BCB - $(\mathrm{P}<0.001$; Table 1). Furthermore, cleavage and developmental rates of oocytes in the Control vitrified group (vitrified without stain selection) were similar to those in the BCB- group, but they were also lower than those selected as $\mathrm{BCB}+(\mathrm{P}<0.001)$. Finally, developmental rates in the Control fresh group were greater than those in the three vitrification groups. No interactions were detected between $\mathrm{BCB}$ staining and oocyte stage of maturity and vitrification solution.

The effect of oocyte stage of maturation on developmental and cleavage rates is depicted in Table 2. Although cleavage rates were similar for immature and in vitro matured oocytes after thawing, blastocyst rates were significantly higher in immature than in in vitro matured vitrified oocytes $(P<0.001$; Table 2$)$.

The effects of vitrification solution on developmental and cleavage rates are depicted in Table 3 . The addition of hyaluronan to the vitrification solution (VS2) had no significant effect on cleavage and blastocyst rates. However, developmental rates of both vitrification groups were significantly lower than those from nonvitrified oocytes (Control fresh group; $\mathrm{P}<0.001$ ).

Table 1. Cleavage and blastocyst rates (means \pm SEM) of vitrified-thawed bovine oocytes selected or not by brilliant cresyl blue (BCB).

\begin{tabular}{|c|c|c|c|}
\hline $\begin{array}{c}\mathrm{BCB} \\
\text { Selection }\end{array}$ & $\begin{array}{c}\text { No. } \\
\text { Oocytes }\end{array}$ & $\begin{array}{c}\text { Cleavage rate } \\
\%\end{array}$ & $\begin{array}{c}\text { Blastocyst rate } \\
\%\end{array}$ \\
\hline $\mathrm{BCB}+$ & 442 & $46.1 \pm 2.4^{\mathrm{b}}$ & $5.0 \pm 0.63^{b}$ \\
\hline $\mathrm{BCB}-$ & 446 & $32.1 \pm 2.0^{\mathrm{c}}$ & $1.0 \pm 0.4^{\mathrm{c}}$ \\
\hline Control vitrified & 200 & $40.0 \pm 4.0^{\mathrm{c}}$ & $2.0 \pm 1.1^{\mathrm{c}}$ \\
\hline Control fresh (not vitrified) & 220 & $62.9 \pm 2.4^{\mathrm{a}}$ & $32.0 \pm 2.4^{\mathrm{a}}$ \\
\hline \multicolumn{4}{|c|}{$\begin{array}{l}\mathrm{a}, \mathrm{b}, \mathrm{c} \text { Rates in the same column with different superscripts differ significantly, } \mathrm{P}<0.05 \text {. } \mathrm{BCB}+\text { : Oocytes selected a } \\
\text { brilliant cresyl blue positive; BCB -: Oocytes selected as Brilliant cresyl blue negative; Control vitrified: oocyte } \\
\text { vitrified without BCB selection; Control fresh: oocytes without any treatment. }\end{array}$} \\
\hline Type of oocyte & $\begin{array}{c}\text { No. } \\
\text { Oocytes }\end{array}$ & $\begin{array}{c}\text { Cleavage rate } \\
\%\end{array}$ & $\begin{array}{c}\text { Blastocyst rate } \\
\%\end{array}$ \\
\hline Immature & 496 & $44.8 \pm 1.9^{\mathrm{b}}$ & $4.0 \pm 0.6^{\mathrm{b}}$ \\
\hline Mature & 392 & $38.3 \pm 2.8^{\mathrm{b}}$ & $2.5 \pm 0.6^{\mathrm{c}}$ \\
\hline Control fresh (not vitrified) & 220 & $62.9 \pm 2.4^{\mathrm{a}}$ & $32.0 \pm 2.4^{\mathrm{a}}$ \\
\hline
\end{tabular}

${ }^{\mathrm{a}, \mathrm{b}, \mathrm{c}}$ Rates in the same column with different superscripts differ significantly, $\mathrm{P}<0.05$

Table 3. Cleavage and blastocyst rates (means \pm SEM) of bovine oocytes vitrified in two different vitrification solutions composed or not with hyaluronan.

\begin{tabular}{lccc}
\hline $\begin{array}{c}\text { Vitrification } \\
\text { Solution }\end{array}$ & $\begin{array}{c}\text { No. } \\
\text { Oocytes }\end{array}$ & $\begin{array}{c}\text { Cleavage rate } \\
\%\end{array}$ & $\begin{array}{c}\text { Blastocyst rate } \\
\%\end{array}$ \\
\hline VS1 & 445 & $39.3 \pm 2.6^{\mathrm{b}}$ & $2.7 \pm 0.6^{\mathrm{b}}$ \\
VS2 & 443 & $43.7 \pm 2.3^{\mathrm{b}}$ & $3.8 \pm 0.7^{\mathrm{b}}$ \\
Control fresh (not vitrified) & 220 & $62.9 \pm 2.4^{\mathrm{a}}$ & $32.0 \pm 2.4^{\mathrm{a}}$ \\
\hline
\end{tabular}

$\overline{\mathrm{a}, \mathrm{b}}$ Rates in the same column with different superscripts differ significantly, $\mathrm{P}<0.05$. VS1: oocytes vitrified in $10 \%$ (v/v) ethylene glycol for $10 \mathrm{~min}$, followed by $20 \% \mathrm{EG}+0.2 \mathrm{M}$ trehalose for $30 \mathrm{sec}$ and subsequently in a $30 \% \mathrm{EG}+$ $0.5 \mathrm{M}$ trehalose for $30 \mathrm{sec}$. VS2: oocytes vitrified in $10 \% \mathrm{EG}$ solution for $10 \mathrm{~min}$, followed by $20 \% \mathrm{EG}+0.2 \mathrm{M}$ trehalose for $30 \mathrm{sec}$, and subsequently in $30 \% \mathrm{EG}+0.5 \mathrm{M}$ trehalose $+0.1 \mathrm{mg} / \mathrm{ml}$ of hyaluronan for $30 \mathrm{sec}$. Control fresh: oocytes without any treatment. 


\section{Discussion}

Although blastocyst production was in general very low with vitrified oocytes, the results of the present study have shown that selection of oocytes using BCB may be a viable alternative to improve survival rates of vitrified oocytes.

The proportion of oocytes that are now utilized for in vitro production and cryopreservation in the commercial bovine in vitro embryo production is very low (Hwang and Hochi, 2014). To obtain successful results it is important to have oocytes with good quality and competence (Sirard et al., 2006), because only a percentage of the recovered oocytes may survive the vitrification process.

Most in vitro production laboratories used the morphological evaluation to select oocytes of "good" quality, demonstrating that there is a correlation between the integrity of cytoplasm and COCs with oocyte competence and consequently blastocyst production rates (Hawk and Wall, 1994; Fair, 2003; Merton et al., 2003; Pontes et al., 2010). Nevertheless, $\mathrm{BCB}$ staining has been shown to enhance these rates when immature oocytes were selected using G6DPH activity (Rodriguez-Gonzalez et al., 2003; Pujol et al., 2004; Alm et al., 2005; Wu et al., 2007; Opiela et al., 2008; Pereira et al., 2010; Silva et al., 2013). In the present study, BCB positive oocytes had higher developmental rates after thawing than $\mathrm{BCB}$ negative oocytes. Furthermore, BCB positive oocytes had greater developmental rates than the non BCB selected group of oocytes in the vitrification control group. These results also confirm those of other studies which demonstrated that $\mathrm{BCB}$ have the capacity to identify oocytes with higher developmental competence (Rodríguez-Gonzalez et al., 2003; Alm et al., 2005; Wu et al., 2007; Manjunath et al., 2007; Ishizaki et al., 2009; Heleil and Fayed, 2010; Silva et al., 2013). Moreover, the higher blastocyst rates obtained from the oocytes selected as $\mathrm{BCB}+$ after warming in comparison with the other groups, confirm the observation of Hadi et al. (2010), in which more $\mathrm{BCB}+$ oocytes developed to the MII stage than oocytes not selected by BCB prior to vitrification.

In this experiment, we obtain an enhancement of our embryo production. With the $\mathrm{BCB}+$ group, we had $3 \%$ more blastocyst than the control group without any selection, that in terms of numbers were 20 more embryos for the oocytes selected as $\mathrm{BCB}+(\mathrm{n}=25)$ than the selected as BCB - $(n=5)$. This would represent a significant commercial advantage, with a higher number of pregnancies and less waste material on oocytes that could not be suitable for IVF or vitrification. This chemical selection demonstrated to be more efficient and accurate than the subjective visual assessment of oocyte quality.

Regarding vitrification, different survival rates after thawing have been reported between mature and immature oocytes. Some authors suggested that immature oocytes are more cryosensitive due to their low membrane stability and the susceptibility of their cytoskeleton (Men et al., 2002), but others observed increased chromosomal abnormalities, alterations of the distributions of cortical granules and alterations in the meiotic spindle in mature oocytes (Hyttel et al., 2000). However, all these reports (Hyttel et al., 2000; Men et al., 2002) are variable and even contradictory, due to the differences between protocols and laboratory procedures. Our results indicated that matured oocytes are more susceptible to vitrification damage because they presented lower developmental rates after thawing than immature oocytes.

Our results are in agreement with those reported by Le Gal and Massip (1999), Magnusson et al. (2008) and Zhou et al. (2010). The lower survival rates in in vitro matured oocytes were probably due to the expansion of cumulus cells that result in an increased area and volume, and also permeability changes that made them more sensitive to cryopreservation (Agca et al., 1998; Wang et al., 2010).

In relation to vitrification solutions, cleavage and blastocyst rates of oocytes vitrified with the addition of hyaluronan in the VS2 solution were only numerically (not significantly) higher than those from oocytes vitrified in solutions without hyaluronan (VS1). Previous studies reported an improved embryo cryosurvival after thawing when hyaluronan was added to the culture media (Stockjovic et al., 2002; Palasz et al., 2008, 2009; Block et al., 2009) or during a dehydration process previous to cryopreservation (Sheehan et al., 2007). Therefore, the use of hyaluronan may be more effective when used in a pre-incubation process prior to cryopreservation rather than adding hyaluronan to the vitrification solution itself, as was done in the present study. According to our results, Palasz et al. (2000) demonstrated the efficacy of sodium hyaluronan $(\mathrm{SH})$ in the freezing solutions as a replacement for other macromolecules as BSA or embryo transfer surfactant (ETS), but no improvements were detected compared to BSA or surfactant.

In conclusion, the selection of oocytes by $\mathrm{BCB}$ and the use of immature oocytes increased the development rates of vitrified-warmed oocytes. However, the addition of hyaluronan in the vitrification solutions did not enhance oocyte survival rate after warming. Finally, bovine oocyte cryopreservation still requires further improvements before it can be successfully used in the field.

\section{References}

Agca YJ, Liu AT, Peter ES, Critser JK. 1998. Effect of developmental stage on bovine oocyte plasma membrane water and cryoprotectant permeability characteristics. Mol Reprod Dev, 49:408-415.

Albarracin JL, Morato R, Izquierdo D, Mogas T. 2005. Vitrification of calf oocytes: effects of maturation 
stage and prematuration treatment on the nuclear and cytoskeletal components of oocyte and their subsequent development. Mol Reprod Dev, 72:239-249.

Alm H, Torner H, Löhrke B, Viergutz T, Ghoneim IM, Kanitz W. 2005. Bovine blastocyst development rate in vitro is influenced by selection of oocytes by brilliant cresyl blue staining before IVM as indicator for glucose-6-phosphate dehydrogenase activity. Theriogenology, 63:2194-2205.

Ambrosini G, Andrisani A, Porcu E, Rebellato E, Revelli A, Casert D, Cosmia E, Marci R, Moscarini M. 2006. Oocytes cryopreservation: State of art. Reprod Toxicol, 22:250-262.

Antosik P, Kempisty B, Bukowska D, Jackowska M, Wlodarczyk R, Budna J, Brussow KP, Lianeri M, Jagodzinski PP, Jaskowski JM. 2009. Follicular size is associated with the levels of transcripts and proteins of selected molecules responsible for the fertilization ability of oocytes of pubertal gilts. J Reprod Dev, 55:588-593.

Block J, Bonilla L, Hansen PJ. 2009. Effect of addition of hyaluronan to embryo culture medium on survival of bovine embryos in vitro following vitrification and establishment of pregnancy after transfer to recipients. Theriogenology, 71:1063-1071.

Dattena M, Mara L, Bin AA, Cappai P. 2007. Lambing rate using vitrified blastocysts is improved by culture with BSA and hyaluronan. Mol Reprod Dev, 74:42-47.

De Loos FP, Van Maurik T, Van Beneden, Kruip TAM. 1992. Structural aspects of bovine oocyte maturation in vitro. Mol Reprod Dev, 31:208-214.

Dinnyes A, Dai Y, Jiang S, Yang X. 2000. High development rates of vitrified bovine oocytes following parthenogenetic activation, in vitro fertilization, and somatic cell nuclear transfer. Biol Reprod, 63:513-518.

Fair T. 2003. Follicular oocyte growth and acquisition of developmental competence. Anim Reprod Sci, 78:203-216.

Ghanem N, Holker M, Rings F, Jennen D, Tholen E, Sirard MA, Torner H, Kanitz W, Schellander K, Tesfaye D. 2007. Alterations in transcript abundance of bovine oocytes recovered at growth and dominance phases of the first follicular wave. BMC Dev Biol, 7:119.

Hadi H, Wahid H, Rosnina Y, Daliri M, Dashrizad M, Karamishabankareh H, Faizah A, Iswadi MI, Abas Mazni O. 2010. Selection of immature bovine oocytes using brilliant cresyl blue enhances nuclear maturity after vitrification. J Anim Vet Adv, 9:27102713.

Hawk HW, Wall RJ. 1994. Improved yields of bovine blastocysts from in vitro-produced oocytes. I. Selection of oocytes and zygotes. Theriogenology, 41:1585-1594.

Heleil B, Fayed M. 2010. Developmental competence of buffalo oocytes from follicles of different diameters selected by BCB staining. Global Vet, 4:176-184.

Hurtt AE, Landim-Alvarenga F, Seidel Jr GE,
Squires EL. 2000. Vitrification of immature and mature equine and bovine oocytes in an ethylene glycol, ficoll and sucrose solution using open-pulled straws. Theriogenology, 54:119-128.

Hwang IS, Hochi S. 2014. Recent progress in cryopreservation of bovine oocytes. Biomed Res Int, $1: 1-11$.

Hyttel P, Vajta G, Callesen H. 2000. Vitrification of bovine oocytes with the open pulled straw method: ultrastructural consequences. Mol Reprod Dev, 56:8088.

Ishizaki C, Watanabe H, Bhuiyan MM, Fukui Y. 2009. Developmental competence of porcine oocytes selected by brilliant cresyl blue and matured individually in a chemically defined culture medium. Theriogenology, 72:72-80.

Kobayashi Y, Okarnoto A, Nishinari K. 1994. Viscoelasticity of hyaluronic acid with different molecular weight. Biorheology, 31:235-44.

Le Gal F, Massip A. 1999. Cryopreservation of cattle oocytes: effects of meiotic stage, cycloheximide treatment, and vitrification procedure. Cryobiology, 38:290-300.

Leibo SP. 1980. Water permeability and its activation energy of fertilized and unfertilized mouse ova. $J$ Membr Biol, 53:179-188.

Magnusson V, Feitosa WB, Goissis MD, Yamada C, Tavares LMT, Ortiz ME, Assumpcao DA, Visintin JA. 2008. Bovine oocyte vitrification: effect of ethylene glycol concentrations and meiotic stages. Anim Reprod Sci, 106:265-273.

Manjunath BM, Gupta PS, Devaraj M, Ravindra JP, Nandi S. 2007. Selection of developmentally competent buffalo oocytes by brilliant cresyl blue staining before IVM. Theriogenology, 68:1299-1304.

Men H, Monson RL, Rutledge JJ. 2002. Effect of meiotic stages and maturation protocols on bovine oocyte's resistance to cryopreservation. Theriogenology, 57:1095-1103.

Merton JS, de Roos APW, Mullaart E, de Ruigh L, Kaal L, Vos PLAM, Dieleman SJ. 2003. Factors affecting oocyte quality and quantity in commercial application of embryo technologies in the cattle breeding industry. Theriogenology, 59:651-674.

Morató R, Izquierdo D, Paramio MT, Mogas T. 2008. Cryotops versus open-pulled straws (OPS) as carriers for the cryopreservation of bovine oocytes: effects on spindle and chromosome configuration and embryo development. Cryobiology, 57:137-141.

Opiela J, Katska-Ksiazkiewics L, Lipinski D, Slomski R, Bzowska M, Rynska B. 2008. Interactions among activity of glucose- 6-phosphate dehydrogenase in immature oocytes, expression of apoptosis-related genes Bcl-2 and Bax, and developmental competence following IVP in cattle. Theriogenology, 69:546-555.

Palasz AT, Thundathil J, Verrall RE, Mapletoft RJ. 2000. The effect of macromolecular supplementation on the surface tension of TCM-199 and the utilization of 
growth factors by bovine oocytes and embryos in culture. Anim Reprod Sci, 58:229-240.

Palasz AT, Rodriquez-Martinez H, Beltran-Brena P, Perez-Garnelo S, Martinez MF, Gutierrez-Adan A. 2006. Effects of hyaluronan, BSA, and serum on bovine embryo in vitro development, ultrastructure, and gene expression patterns. Mol Reprod Dev, 73:1503-1511.

Palasz AT, Brena PB, Martinez MF, Perez-Garnelo SS, Ramirez MA, Gutierrez-Adan A. 2008. Development, molecular composition and freeze tolerance of bovine embryo cultured in TCM-199 supplemented with hyaluronan. Zygote, 16:39-47.

Palasz AT, Beltran Breña P, De la Fuente J, Gutierrez-Adan A. 2009. The effect of bovine embryo culture without proteins supplements until day 4 on transcription level of hyaluronan synthases, receptors and mtDNA content. Zygote. 18: 121-129.

Papis K, Shimizu M, Izaike Y. 2000. Factors affecting the survivability of bovine oocytes vitrified in droplets. Theriogenology, 54:651-658.

Pawlak P, Pers-Kamczyc E, Renska N, Kubickova S, Lechniak D. 2011. Disturbances of nuclear maturation in BCB positive oocytes collected from peri-pubertal gilts. Theriogenology, 75:832-840.

Pereira GR, Lorenzo PL, Carneiro GF, BilodeauGoeseels S, Kastelic JP, Esteller-Vico A, LiuaPereira IKM. 2010. Selection of developmental competence immature equine oocytes by brilliant cresyl blue prior to maturation with equine growth hormone in vitro. Anim Reprod Sci, 121:S248-S249.

Pontes JHF, Silva KCF, Basso AC, Rigo AG, Ferreira CR, Santos GMG, Sanches BV, Porcionato JPF, Vieira PHS, Faifer FS, Sterza FAM, Schenk JL, Seneda MM. 2010. Large-scale in vitro embryo production and pregnancy rates from Bos taurus, Bos indicus, and indicus-taurus dairy cows using sexed sperm. Theriogenology, 74:1349-1355

Pujol M, López-Béjar M, Paramio MT. 2004. Developmental competence of heifer oocytes selected using the brilliant cresyl blue (BCB) test. Theriogenology, 61:735-744.

Rodríguez-González E, López-Béjar M, Velilla E, Paramio MT. 2002. Selection of prepubertal goat oocytes using the brilliant cresyl blue test. Theriogenology, 57:1397-1409.

Rodríguez-González E, López-Bejar M, Izquierdo D, Paramio MT. 2003. Developmental competence of prepubertal goat oocytes selected with brilliant cresyl blue and matured with cysteamine supplementation. Reprod Nutr Dev, 43:179-187.

Rodriguez-Villamil P, Ongaratto FL, Fernandez Taranco M, Bó GA. 2013. Solid-surface vitrification and in-straw dilution after warming of in vitro-produced bovine embryos. Reprod Domest Anim, 49:79-84.

Sheehan CB, Larman MG, Gardner DK. 2007. Bovine oocyte vitrification is improved by increased pyruvate concentration and the inclusion of hyaluronan in the vitrification medium. Reprod Fertil Dev, 19:183.
Silva DS, Rodriguez P, Galuppo A, Arruda NS, Rodrigues JL. 2013. Selection of bovine oocytes by brilliant cresyl blue staining: effect on meiosis progression, organelle distribution and embryo development. Zygote, 21:250-255.

Sirard MA, Richard F, Blondin P, Robert C. 2006. Contribution of the oocyte to embryo qualtity. Theriogenology, 65:126-136.

Sripunya N, Somfai T, Inaba Y, Nagai T, Imai K, Parnpai R. 2010. A comparison of Cryotop and solid surface vitrification for cryopreservation of in vitro matured bovine oocytes. J Reprod Dev, 56:176-181.

Stojkovic M, Kölle S, Peinl S, Stojkovic P, Zakhartchenko V, Thompson JG, Wenigerkind H, Reichenbach HD, Sinowatz F, Wolf E. 2002. Effects of high concentrations of hyaluronan in culture medium on development and survival rates of fresh and frozenthawed bovine embryos produced in vitro. Reproduction, 124:141-153.

Tian WN, Braunstien LD, Prang J, Stuhlmeir KM, Xiq C, Tian X, Statin RC. 1998. Importance of G6DPH activity for cell growth. $J$ Biol Chem, 273:10609-10617.

Toole BP. 2001. Hyaluronan in morphogenesis. Semin Cell Dev Biol, 12:79-87.

Torner H, Ghanem N, Ambros C, Hölker M, Tomek W, Phatsara C, Alm H, Sirard MA, Kanitz W, Schellander K, Tesfaye D. 2008. Molecular and subcellular characterisation of oocytes screened for their developmental competence based on glucose-6phosphate dehydrogenase activity. Reproduction, 135:197-212.

Tríbulo A, Rogan D, Tribulo H, Tribulo R, Alasino RV, Beltramo D, Bianco I, Mapletoft RJ, Bó GA. 2011. Superstimulation of ovarian follicular development in beef cattle with a single intramuscular injection of Folltropin-V. Anim Reprod Sci, 129:7-13.

Urdaneta A, Jimenez-Macedo AR, Izquierdo N, Paramio MT. 2003. Supplementation with cysteamine during maturation and embryo culture on embryo development of prepuberal goat oocytes selected by brilliant cresyl blue test. Zygote, 11:347-354.

Vajta G, Holm P, Kuwayama M, Booth PJ, Jacobsen H, Greve T, Callesen H. 1998. Open pulled straw (OPS) vitrification: a new way to reduce cryoinjuries of bovine ova and embryos. Mol Reprod Dev, 5:53-58.

Vieira AD, Forell F, Feltrin C, Rodrigues JL. 2008. Calves born after direct transfer of vitrified bovine in vitro-produced blastocysts derived from vitrified immature oocytes. Reprod Domest Anim, 43:314-318.

Wang X, Al Naib A, Sun DW, Lonergan P. 2010. Membrane permeability characteristics of bovine oocytes and development of a step-wise cryoprotectant adding and diluting protocol. Cryobiology, 61:58-65.

Wongsrikeao P, Otoi T, Yamasaki H, Agung B, Taniguchi M, Naoi H, Shimizu R, Nagai T. 2006. Effects of single and double exposure to brilliant cresyl blue on the selection of porcine oocytes for in vitro 
production of embryos. Theriogenology, 66:366-372.

Wu YG, Liu Y, Zhou P, Lan GC, Han D, Miao DQ,

Tan JH. 2007. Selection of oocytes for in vitro maturation by brilliant cresyl blue staining: a study using the mouse model. Cell Res, 17:722-731.
Zhou XL, Naib A, Sun DW, Lonergan P. 2010.

Bovine oocyte vitrification using the Cryotop method: effect of cumulus cells and vitrification protocol on survival and subsequent development. Cryobiology, 61:66-72. 